\title{
Subjetividade e corporalidade: elementos da arte digital
}

Subjectivity and corporality: elements of digital art

Vaneza Rita Silva Melo 


\section{Resumo}

O presente trabalho faz uma reflexão sobre a arte digital e a relação que se estabelece entre o sujeito e o próprio corpo. Para entender esta relação, que inclui uma visão social e filosófica, elencaram-se características importantes da história da arte moderna e seus desdobramentos até chegar à arte digiltal. Os conceito de subjetividade e corporalidade são incorporados para explanar sobre a poética proposta na exposição $A$ Arte Somos Nós que servirá como um estudo de caso.

Palavras-chave: Subjetividade; Tecnologia. Corpo; Arte Digital.

\section{Abstract}

The present work is a reflection on the digital art and the relationship established between the subject and his own body. To understand this relationship, which includes a social and philosophical view, we listed the important features of the history of modern art and its developments up to the digital art. The concept of subjectivity and corporality are incorporated to explain about the poetic proposal in the exhibition We Are The Art which will serve as a case study.

Keywords: Subjectivity; Technology. Body; Digital Art.

ISSN: $2175-2346$ 


\section{Introdução}

Mediar a questão da arte na cultura digital requer perpassar os olhos sobre uma historicidade, um entendimento sobre a percepção do mundo, ora observando os discursos propostos, ora nos afastando de pensamentos estanques que podem deixar dúvida ao pensarmos sobre o diálogo homem e máquina.

Ao longo do século $\mathrm{XX}$, artistas recorreram à tecnologia para expressar um momento e, ao mesmo tempo, inserirem-se num patamar diferenciado em sociedade. Como Charles Harrison postula, esses artistas utilizaram palavras como moderno e modernismo, na busca de acompanhar o tempo presente. (HARRISON, 2001, p.9-10)

Os futuristas e a questão da velocidade exemplificam quanto o tema tecnologia se tornara central para o processo artístico desse período. E por mais que a própria história da arte ocidental nos revele nomes que nada nos dizem sobre tecnologia, no sentido restrito de máquina como anteparo para o fazer da obra, as primeiras três décadas do século XX tiveram, sim, artistas que já se preocupavam em como criar obras que abrigassem essa ideia. É o caso de Marcel Duchamp, que criou "uma máquina motorizada formada por círculos desenhados no papel, colocados sobre uma placa rotativa. Quando a máquina girava, os desenhos pintados sobre sua placa circular pareciam formar círculos concêntricos, causando um efeito de espiral". Era a obra Discos espirais, criada em 1923. Outro exemplo é Acessório de luz para um balé ou Modulador de luz e espaço, 1923-1930, obra de Lászlo Moholy-Nage que propunha a utilização da luz e do movimento no campo da arte. "A obra era uma escultura maquínica que desenhava em torno de seu eixo um amplo tecido de luz e sombra". (ARANTES, 2005, pp.38-39)

Para compreender como a arte se apropriou da cultura digital nos dias atuais, escolheu-se criar um fio condutor que expusesse questões relativas aos conceitos de subjetividade, corporalidade, modernismo, moderno, tecnologia e digital.

A subjetividade e corporalidade são retiradas das ideias filosóficas de Merleau -Ponty (1999), que expressa com rigor o quanto o duo sujeito/corpo se relaciona entre si. O filósofo francês dá ênfase à relação que se estabelece com a experiência. Hauser (2003) também oferece um norte quanto ao conceito de subjetividade quando avaliado do ponto de vista social, a partir do romantismo. E a corporalidade é complementada com o pensamento de Seeger, da Matta e Viveiros de Castro (1979), quando a tratam como matriz de símbolos.

O conceito de cultura-mundo é aplicado porque se relaciona diretamente com a era digital. Como Lipovstky e Serroy(2008) relatam, o mundo global parte de premissas que regem a lógica da tecnologia digital. Os olhares de Argan (2004), Hauser (2003), Walther (2010) e Tassinari (2001) mostram a trajetória da arte moderna, permitindo manter um diálogo com Arantes (2005), que tratará de uma retrospectiva da arte digital.

E para confrontar tais informações escolheu-se como estudo de caso a recente exposição realizada na Bahia, intitulada a A Arte Somos Nós, de Zimaldo Melo, que utiliza programação de códigos computacionais, criando algoritmos que resultam em arte. Mais que isso: as obras apresentadas resgatam questões que primam pela subjetividade e corporalidade do observador/participante. Má- 
quina, homem, corpo, movimento, cor, e som se misturam para o fazer da obra. Nessa exposição, o observador é um agente ativo, a ponto de torna-se parte do processo artístico e artista. (MELO, 2014)

\section{A existência da obra de arte}

O século XXI para o campo da arte nada mais é que uma ampla soma do que vem ocorrendo há séculos. Não é à toa que Giulio Carlo Argan(2004) utiliza a história para explicar o conceito da arte; parte da máxima de que a obra tem um valor, parâmetro que e destina a um "exemplar único", constituído de uma força imagética sobre o objeto em questão. Para a consagração, estabelece-se a regra:

[...] "desde sua origem a arte é modelo de produção, enquanto é a atividade que produz objetos detentores do máximo valor. A obra de arte é o objeto único, que tem o máximo de qualidade e o mínimo de quantidade" . Com isso, em meio às relações que as vinculam ao ambiente social, as obras de arte também se diferenciam por um viés ético, pela criação de valores muito particulares. Ao privilegiar a qualidade - como máxima de mediações -, o aspecto único de seus objetos, a arte afirma um fazer específico. (NAVES apud ARGAN, 2004, p.XIX)

Outro ponto que Argan levanta é sobre o próprio pensar do fazer artístico. Não se pode negar que o artista é um pensador. No prefácio escrito por Rodrigo Naves no livro Arte Moderna, há uma indicação explícita por parte do pesquisador italiano no que se refere ao exercício do pensamento e sua relação com a arte. Se "é no fazer que se reconhece a eticidade de um comportamento"2 , a atividade artística é também lugar do fazer ético por excelência - onde sua autonomia de base permite uma interrogação permanente sobre o sentido dos atos." (NAVES apud ARGAN, 2004, p.XIX)

Além da ética, entendendo-se aqui como prática de um exercício filosófico, Argan nos lega também outra questão que afetará a arte chegando aos dias atuais, o que incluirá a arte digital. Trata-se da subjetividade herdada do romantismo. Argan (2004) considera que o início do ciclo romântico na arte é também o moderno, ou até mesmo contemporâneo, "porque chega até nós." (ARGAN, 2004, p.14)

A revolução francesa deu ao homem moderno um dilema que paira entre a liberdade e o dever, gerando o que conhecemos como valor universal. Era o mundo napoleônico, que se valia da arte para expressar suas ideias. Mas a Europa não se resumia à França, e o ideal do universal é rompido com uma nova perspectiva: surge a vontade de resgatar as tradições de seus povos, preservar suas origens, gerando, ao mesmo tempo, uma autonomia, um ideal comum e a razão da existência no âmbito civil. Argan (2004) ainda nos indica que tais fatos, somados ao nascimento da tecnologia industrial, colocarão em xeque tanto o artesanato quanto "as técnicas refinadas e individuais" da arte. Isso transformará a estrutura e a finalidade da própria arte. O sistema industrial impulsiona o surgimento das

1. Argan apud Rodrigo Naves em "La crisi del design", em Storia dell'arte

2. Argan apud Rodrigo Naves em "Salvezza a caduta nell'arte moderna". p.52 come storia della cittá. p.262 
tendências artísticas que se valem das novas poéticas para alcançarem o dito modernismo. Era a ânsia de acompanhar o tempo presente. (ARGAN, 2004, pp. 14-17)

Se do ponto de vista do artista a sua produção precisava de um up-grade para acompanhar os novos acontecimentos do sistema econômico, de outro, a palavra "modernismo", como nos pontua Charles Harrison (2001), professor de história e teoria da arte na Open Universty, não se refere somente a um período que abrange a arte moderna. "Trata-se de uma forma de valor, em geral associada apenas a algumas obras e que serve para distingui-las de outras. Selecionar uma obra como exemplo de modernismo é vê-la como pertencente a uma categoria especial no interior da cultura ocidental do período moderno." (HARRISON, 2001.p.6)

Quando Alberto Tassinari (2001), em seu ensaio O Espaço Moderno, reflete sobre o anteparo artístico e o que aconteceu nos últimos 150 anos na arte ocidental, revela que a negação da perspectiva talvez tenha sido o início de como trabalhar os demais suportes que abrigariam a arte. Tassinari aponta a obra Ponte de Mancy, de Cézzane, realizada entre 1879 e 1890, como o princípio de que tanto a perspectiva quanto o naturalismo já não eram tão importantes. Tal obra mostra uma ponte com arcos sobre um lago. Mas não é uma representação exata, há perda de perspectiva. A profundidade e o ponto de fuga são vagos à percepção. Não há mais a representação do real. (TASSINARI, 2001. pp.17-25)

A trajetória da arte, daí em diante, foi utilizar a tela como anteparo para outros experimentos como poderia se ver em Braque, Picasso, Mondrian, só para citar os nomes de mestres do início do século XX. Só em 1950, com a obra Ritmo de Outono, de Jackson Pollock, é que o corpo será espacializado na tela. Não há mais pinceladas, mas a tinta goteja sobre o anteparo, de acordo com os movimentos proposto pelo artista. Muda-se assim a percepção do artista sobre a tela, que vai do cavalete ao chão, durante o processo da obra de arte. A obra de Pollock é considerada por Tassinari como o fim da formação da arte moderna. Dessa maneira, doravante, o que se verá (ou sentirá) serão os desdobramentos da arte. (TASSINARI, 2001, pp.29-33)

A fase de desdobramento da arte moderna tem início com Jasper Johns, em 1956. A obra Tela, encáustica e colagem sobre madeira e tela, representa a mudança, pois há um novo olhar sobre o espaço da arte, no caso, o anteparo: a moldura e a colagem se confundem, relativizando a questão do espaço e da obra com o exterior. E é a partir desta obra que Tassinari afirmará que a arte moderna cessará em sua fase de formação e entrará para a fase de desdobramento. (TASSINARI, 2001, p.10)

A fase de desdobramento caberá também à arte digital. É nesta fase que a arte, a ciência e a tecnologia somaram a outra possibilidade do fazer artístico, chegando a envolver o observador-participador. Desde as primeiras décadas do século XX, havia um interesse de propor uma estética que expressasse os ideais da sociedade industrial. O Manifesto futurista exemplifica bem como alguns artistas pensavam: os valores não estavam centrados no passado, mas sim nos elementos que representassem a tecnologia. A velocidade era o elemento presente nas obras, era o que a tornava um objeto dinâmico, capaz de inserir em si o fluxo espaço-tempo. Após os futuristas entrarem em ação, ainda mesmo que explorando o elemento velocidade em telas e em esculturas em formatos tradicionais, outros artistas se valeram de experimentações tecnológicas como László Moholy-Nagy (Modulador de luz e espaço, 
1923-1930/ escultura maquínica), Jean Tinguely (Homenagem a Nova York, 1960/ escultura cinética), Nicholas Shöffer (Construção-Cibernética-Espaço-Dinâmica, 1956/ utiliza dispositivos de controle para mover arranjo escutural). (ARANTES, 2005, p.39)

No final dos anos 1960, Billy Klüver, Robert Rauchemberg e outros artistas fundaram em Nova York o grupo Experimentos em Arte e Tecnologia (EAT), para atuar na interface da arte com a tecnologia. Um dos objetivos do grupo era possibilitar o desenvolvimento de propostas artísticas realizadas em co-autoria entre artistas e engenheiros sob uma perspectiva interdisciplinar. [...] No final dessa década, o curador e historiador Pontus Hultén inaugurou no Museu de Arte Moderna de Nova York uma das primeiras exposições de arte e tecnologia: The Machine as Seen at the End of Mechanical Age, o que revelou, de certa forma, a entrada da área de arte e tecnologia para o mainstream artístico. (ARANTES, 2005, p. 41)

As formas de expressar-se no campo da arte com a apropriação de recursos tecnológicos desenvolvidos pelas indústrias criam um terreno fértil para o fazer da arte. A geração das propostas estéticas se vale agora do áudio, do tátil, do visual. $O$ que se pode entender é que a arte digital é um desdobramento dentro do contexto da produção artística contemporânea, como afirma Arantes (2005). Do passado que questionava a utilização da tecnologia à autoafirmação do modernismo, a obra de arte dentro da cultura digital ganhou valor porque são experimentações que subvertem o sistema que permite o fomento de tal cultura. Trata-se do novo espaço a ser trabalhado. É o sistema e o usuário, é a tela e o operador, é a obra e o participador, é o homem e a máquina. (ARANTES, 2005, pp.24-25)

A aplicação deste pensamento pode ser vista em na exposição individual do artista Zimaldo Melo, intitulada Arte Somos Nós. Das obras apresentadas, três utilizaram programas computacionais. Realizada na Bahia, em 2014, a questão levantada pela curadoria, formada por Antonio Carlos Portela e Dilson Midlej, permeia a vivência entre o homem e a máquina e articula um pensar sobre que espaço novo é este que se apresenta a obra e qual o papel do fruidor na arte desta dita contemporaneidade.

\section{O sujeito e a sociedade}

Mas por que o espaço destinado à arte sofreu tal mudança? Se há algo que a arte moderna faz e refaz é negar, gradualmente, a estética tradicional que remota, para este trabalho, de um período que tem início no romantismo. Como Hauser (2003) sinaliza, a questão da subjetividade, a formação individual, irá se manifestar em diversos países da Europa por meio das artes, seja na literatura, na pintura ou na música. $O$ que se reafirmará, doravante, é a essência do homem moderno.

O romantismo não era apenas um movimento europeu de caráter universal, conquistando uma nação após a outra e criando uma linguagem literária universal que, em última análise, era tão inteligível na Rússia, e na Polônia quanto na Inglaterra e na França; ele também provou ser uma daquelas correntes que, como o naturalismo gótico e o classicismo na Renascença, substituiu como fator duradouro no desenvolvimento da arte. Na verdade, não existe produto da arte moderna, nenhum impulso emocional, nenhuma impressão ou estado de espírito do homem moderno, que não deva sua sutileza e variedade à sensibilidade que se 
desenvolveu a partir do romantismo. Toda exuberância, anarquia e violência da arte moderna, seu lirismo balbuciante, seu exibicionismo irrestrito e profuso, derivaram dele. (HAUSER, 2003, p.664)

O romantismo é a chave para ideia de sujeito. É uma valorização do indivíduo que se acentuará no século XIX quando a industrialização nos trará a imposição de novos hábitos - como valorizar o tempo e o novo, no sentido de atual, exigindo que a mão de obra produza mais e mais para saciar uma legião de anônimos que incorporam o consumo como uma via para se socializar. Portanto, indústria, consumo e sujeito serão o tripé para entendermos o que é moderno.

Lipovetsky e Serroy (2008) afirmam que a própria ideia de moderno, na atualidade, consiste numa recomposição, num arranjo em que o moderno nada mais é que uma ampliação, multiplicação ou expansão do que se iniciou há alguns séculos. A novidade está no conceito - um tanto arriscado como os autores mesmo pontuam - de cultura na contemporaneidade. O que se avalia é que tanto o lado social quanto econômico dentro da Hipermodernidade ${ }^{3}$ servem de parâmetro para indicar o que seria usual ou não. Para estes autores, a cultura não é mais vista como algo à parte, setorial, característico de um só grupo. A cultura está intimamente ligada ao mundo e às suas vivências e se desloca por territórios geopolíticos cada vez mais homogêneos do ponto de vista das ações empregadas. Lipovestky e Serroy justificam isso com a expressão "tecnocapitalismo planetário", que expõe o quanto a tecnologia avança no sentido de aproximar os continentes; um exemplo seriam as redes sociais, que são ao mesmo tempo a base do próprio consumo. Para estar na rede, é preciso de computador, celular ou tablat, produtos e mantenedores da ideia do que é moderno. (LIPOVESTKY, SERROY, 2008, p.7)

O conceito de cultura-mundo está empregado na tecnociência que gera produtos, no mercado que compra e vende estes produtos, no indivíduo ou sujeito que se transforma em consumidor, nas mídias que veiculam as informações do feitos da tecnociência e no próprio consumo ao serializar até mesmo cidades, tornando-as o resultado de uma construção de valores, objetivos e mitos. (LIPOVESTKY, SERROY, 2008, pp.10-11)

O sistema também consolidou o chamado turismo cultural para vender arte. Ampliou-se o acesso aos domínios artístico e cultural quando cidades se valem de seus monumentos, personalidades e obras para atrair visitantes. Arte e cultura são elementos, agora, do mercado turístico. De acordo com Lipovestky e Serroy, a arte e a cultura tornaram-se produtos que geram lucro, publicidade e promoções. Na França, por exemplo, "o fenômeno assumiu tal amplitude que os especialistas concordam em estimar que o turismo cultural representa hoje $10 \%$ do montante de negócios gerado pelo conjunto do setor." (LIPOVESTKY, SERROY, 2008, p.92)

Dois alicerces são propostos para a arte na hipermodernidade. $O$ primeiro refere-se ao status do próprio artista. O segundo, ao poder mercadológico estabelecido por este sistema com relação à arte. Na década de 1960, a arte flerta tanto com a moda quanto com a publicidade. O próprio Andy Warhol não pode mais ser consi-

3. Este superlativo é cunhado pelo filósofo Gilles Lipovetsky em seu livro "Os tempos hipermodernos", disponivel em http://pt.scribd.com/doc/17062062/Os-

Tempos-Hipermodernos-Gilles-Lipovetsky . Acesso em 29 mai 2014. 
derado um artista que se opõe ao sistema capitalista. Warhol mostra que a arte pode absorver os signos do capitalismo e ser rentável para quem a produz. A pobreza não mais era tão inspiradora. Os artistas buscam, então, fama e dinheiro. Assim, chegamos aos artistas-celebridades, aqueles que se valem dos sistemas midiáticos e mercantis. (LIPOVESTKY, SERROY, 2008. p.87)

\begin{abstract}
O momento não é mais da glória imortal; é o da busca de uma celebridade midiática que assegure ser comprado e apanhado nas redes de promoção internacional. Fim da época de Van Gogh e das telas de valor póstumo do gênio desconhecido durante sua vida; o valor de uma obra não está na cotação do artista, que é inseparável de todo o trabalho de espetacularização e de provocação, de promoção midiática, de construção e de comunicação de uma imagem que passa pelos catálogos e exposição, pela rede internacional das galerias e das instituições culturais. $\mathrm{Na}$ era da hipermodernidade, ser artista não é mais apenas criar obras das quais se espera que sejam reconhecidas no futuro; é trabalhar em comunicar uma imagem, é figurar no kunst Kompass ${ }^{4}$, é estar cada vez mais presente e hipervisível no mercado mundial da arte. (LIPOVESTKY, SERROY, 2008, pp.87-88)
\end{abstract}

Este é o novo regime da arte: enquanto atrai um vasto público, dá vida a muitas atividades comerciais ligadas a elas, ocupa as páginas das revistas, consagra estrelas, torna-se ela própria empresa e objeto de especulação. Levada pelo mercado, torna-se arte-mundo, arte no mundo. Se isso a torna acessível a todos, ao mesmo tempo, contribui para confundir sua imagem, criando um efeito complementar de desorientação. O que parecia de fato escapar à lógica mercantil e constituía para muitos um último refúgio - o mundo puro, gratuito, transcendente mesmo, de Beleza - alinha-se cada vez mais às leis gerais do mundo mercantil, midiático e consumista. (LIPOVESTKY, SERROY, 2008, pp. 92-93)

Se de um lado temos um sistema social no qual se insere o sujeito, do outro temos que entender a própria concepção do que é o sujeito. Deleuze (apud MANSANO, 2009) entende que o sujeito é constituído de experiência, das informações que pode acumular. Para o pensador francês, as relações de enfrentamento, das lutas, são periféricas, mas conseguem atuar sobre o indivíduo fazendo com que este se manifeste, reaja. Por este motivo, Deleuze defende que o sujeito não é um corpo com uma fórmula pronta, com ideias preestabelecidas. Este se constrói à medida que é capaz de entender estas relações como alicerces de sua formação, percebendo as diferenças e transformando estas ações em atributos que the sejam singulares. (DELEUZE apud MANSANO, 2009, p. 115)

E o corpo nada mais é que a representação vital da percepção do mundo. Para o filósofo Merleau-Ponty, a relação entre sujeito e corpo é o que dará sentido ao processo vital. As sensações são perceptíveis quando o sujeito é observado, pois seu corpo expressa o que apreende. Merleau-Ponty fala que "nosso corpo não tem o poder de fazer-nos ver aquilo que não existe; ele pode apenas fazer-nos crer que nós o vemos." (MERLEAU-PONTY, 1999, p.55)

4. É um indicador da revista alemã Capital e divulga os cem artistas contemporâneos mais bem cotados do mercado internacional. (LIPOVESTKY, SERROY, 2008, p.88) 


\section{Subjetividade e Corporalidade}

A subjetividade como o elemento constituinte da percepção do mundo ganha espaço no campo da arte. Desde a década de 1960, a visão contemplativa do observador, mera ação do sujeito, não era mais o que interessava. O que se queria era que o sujeito interagisse com a obra. Isso ocorrerá em escala mundial, por exemplo, as propostas do grupo Fluxus ao apresentar performances em que o espectador era convidado a participar de uma ação. É o caso de Cut Piece, 1965, realizada por Yoko Ono, em que a plateia pegava uma tesoura, e a artista, sentada no palco, esperava que sua roupa fosse cortada. A proposta era a efemeridade da ação como também a fluidez, o acaso. (ARANTES, 2005, p.78)

Outro questionamento era sobre o próprio anteparo da obra de arte. Dois brasileiros serão referência para tratar tanto do corpo como do suporte da obra dentro do panorama artístico da década de 1960. Lygia Clark e Hélio Oiticica evidenciam a importância de como apresentar a obra de arte e mostram também a insatisfação com o suporte da obra e com a contemplação não mais passiva, agora, sim, interativa. Para ambos, a obra de arte não servia mais como um elemento de contemplação a distância, confinada em um museu, como há séculos havia sido proposto. $O$ público precisava sentir, tatear, tocar e explorar a obra de arte. Oiticica vislumbra o Parangolé, depois de teorizar sobre o corpo, a forma, a expressão e o participador ativo. A complexidade dos elementos da obra de Oiticica nos faz perceber que tanto a subjetividade quanto a corporalidade fazem parte da própria obra.

A relação do corpo com a descoberta do participador (sujeito) será também uma constante na obra de Lygia Clark, que propõe uma organicidade na própria obra. Em 1960, a artista elabora uma série intitulada "Bichos", esculturas metálicas articuladas que, quando o participante manuseia, ganha outra forma, outra aparência. Dentro do universo de Lygia Clark, o que se questionará é a função tanto da arte quanto do artista. A partir desta questão, observamos que se subtrai a sacralização do artista, enquanto detentor único do fazer da obra, e a própria obra torna-se um terreno aberto. Como afirma Milliet (1992 apud MEDEIROS, 2009), "o objeto em si, portanto, não mais é importante, e os significados, agora, emergem dessa encruziIhada de subjetividades, que torna essa descoberta do gesto, do corpo, uma metáfora da liberdade do espectador-autor. (MILLIET, 1992, apud MEDEIROS, 2009, p.5)

A proposta de Lygia Clark consistia no corpo a corpo, obra e sujeito, um confronto e uma dependência. O primeiro porque provoca o sujeito a arriscar e colocar as mãos para explorar a obra, o segundo porque a própria obra já não existe sem o sujeito.

$\mathrm{Na}$ fase sensorial de meu trabalho, denominei nostalgia do corpo, o objeto ainda era um meio indispensável entre a sensação e o participante. $\mathrm{O}$ homem encontra seu próprio corpo através de sensações táteis realizadas em objetos exteriores a si. Depois incorporei o objeto, mas fazendo-o desaparecer. Entretanto, é o homem que assegura o seu próprio erotismo. Ele torna-se objeto de sua própria sensação. [...] A expressão corporal tem aqui uma importância essencial, pois é através dela que as células são construídas, por exemplo, abrindo os braços ou criando com as pernas abertas túneis em que as pessoas possam passar. (CLARK, 1980, pp.36-37) 
Neste trecho, a artista explicita o quanto o próprio corpo pode vir a servir como obra. Sem dúvida, outros artistas, décadas depois, mas já utilizando plataformas computacionais, relacionaram a subjetividade e a corporalidade dentro da proposta artística. É o caso de Jeffrey Shaw e Dirk Groeneveld, que em 1988 criaram uma instalação interativa gráfica intitulada "A Cidade Legível". A partir de um programa de computador, as letras só pareceriam na tela caso o "observador" pedalasse uma bicicleta, fazendo uma alusão do flanar pela cidade. Neste caso, as ruas eram formadas por letra que formavam palavras e frases. A atividade corporal era exigida para que o sujeito/observador entrasse no próprio espaço. O espaço dependia das decisões subjetivas - pedalar ou não pedalar, para ver a tal cidade. (WALTHER, 2010, p.616)

Como nos mostra também Arantes (2009), arte, ciência e tecnologia tornaram-se aliadas para ampliar o próprio conceito de criação artística. Hoje, os satélites e radares captam informação, e o artista retira do material as potencialidades estéticas. São trabalhos em sky-art que sugerem a poética do "invisível". Em 2001, Michael Gleich teve a ideia de criar Web of life. Era um trabalho interativo que contava com uma instalação fixa, localizada no Centro de Arte e Mídia de Karlsruhe, na Alemanha (ZKM), e mais quatro estações móveis, em outras cidades do mundo. $O$ público era convidado a escanear a mão, que era transformada em linhas virtuais. $O$ objetivo era conectar, virtualmente, os cidadãos. O olhar de Jeffey Shaw, responsável pelo desenvolvimento artístico deste trabalho, recai sobre a mão, elemento que identifica o sujeito, já que tem a digital.

A poética desenvolvida por Shaw lembra o conceito de inteligência coletiva, defendido por Pierre Lévy, filósofo francês. A ideia é que a comunicação seja ubíqua. Não importa o lugar, se o indivíduo estiver conectado à rede. Outros dois aspectos que se referem ainda a este conceito são a capacidade de armazenar informações e a capacidade de automatização de operações através de números e símbolos, facilitando a comunicação. Estas ferramentas formam a inteligência coletiva. (LÉVY, 2011)

Não é somente no ambiente das redes digitais, no entanto, que existe a possibilidade de se fazer arte. O computador e o homem se comunicam através de pensamentos ordenados. O que ocorre é que na arte, o homem, por exemplo, cria uma animação capaz de utilizar como suporte a tela do computador. O homem também faz com que máquinas se comuniquem entre si para mostrar sua arte. Para o artista e teórico Edmond Couchot, existem dois caminhos para mostrar trabalhos artísticos: um seria os trabalhos para as telas do computador (que incluem as animações para cinema, por exemplo), a computer art, e o outro seria a arte no campo da interatividade que dependerá da interface. (ARANTES, 2005, pp. 62-64)

Em termos estritamente técnicos, a interface, como se sabe, geralmente é considerada um dispositivo que permite a troca de informações entre os sistemas que podem tanto ser de mesma natureza - por exemplo, dois computadores - como de natureza diferentes - por exemplo, o computador e o usuário. Ela estabelece assim um canal duplo de informação entre o homem e a máquina (input e output), a interface permite que a ação de um homem, desde a mais simples, como apertar um teclado, seja reconhecida, processada pela máquina e desenvolvida pelo usuário. Para que seja possível uma comunicação homem/máquina, portanto, é necessário um ele- 
mento que funcione como tradutor das informações transmitidas pelos usuários à linguagem do ordenador. Nesse sentido, pode-se dizer que a relação governada pela interface é a relação semântica, já que é possível "traduzir" as informações dadas pelos usuários em uma linguagem que o computador entenda - em código binário, em linguagem matemática e numérica. (ARANTES, 2005, pp.64-65)

O que Arantes (2005) nos revela é que a tecnologia digital é essencialmente informação, sendo esta o ponto central de uma obra de arte digital. Somente através de um código binário, programado pelo artista, será possível o observador/participante interagir com a obra que se apresenta de forma visual, ou através do som, do sopro, um deslocamento do corpo no espaço. O trabalho do artista consiste, dentro do contexto da arte digital, em organizar as informações (códigos binários) e sensibilizar o sujeito a ponto de ele mesmo utilizar o corpo para o fazer da obra. (ARANTES, 2005, pp.63-69)

\section{Interface: A Arte Somos Nós}

Se consideramos a interface como uma visão sistêmica, entenderemos que, na prática, funciona como a conexão que poderá existir entre a obra e o público. Para Edmond Couchot (apud Arantes, 2005, p.74), a interface representa a subjetividade na contemporaneidade:

\footnotetext{
De todas as hibridações em direção das quais o numérico se inclina, a mais violenta e decisiva é a hibridação do sujeito e da máquina, através da interface. Violenta porque ela projeta o sujeito - tanto o autor da obra quanto o espectador, o artista quanto o amador de arte - em uma situação nova, em que ele é intimado insistentemente a se redefinir [...]. (COUCHOT apud ARANTES, 2005, p. 74)
}

É o que faz o artista Zimaldo Melo, na exposição A Arte Somos Nós, 2014, na Bahia. Como interface do tema, os curadores Antonio Carlos Portela e Dilson Midlej escolheram obras que dialogassem com o duo homem/máquina: Máquina de Pintura, 2014; Irreprodutibilidade, 2014; Pollock v.1.0, 2013, Repong, 2013, e DesenhoAoVivo, 2013.

Três das obras escolhidas utilizaram programas computacionais. A instalação Pollock v.1.0., 2013, foi elaborada a partir da linguagem Processing, utilizando bibliotecas OpenSource para captar o movimento do corpo e do som emitido pelo sujeito/ observador/participante. O que ocorre é que as cores surgem na tela do computador em formas de respingos, ressignificando o dripping de Jackson Pollock, a partir do movimento do corpo. O programa utiliza as bibliotecas OpenCV para a detecção de faces através da câmera do computador para posicionar o ponto onde a pintura é aplicada, e a biblioteca Minin para captar o som emitido pelo usuário, utilizada para espalhar a tinta na tela. (MELO, 2014, pp.15-49)

O artista também se apropria do clássico videogame Pong, que apresenta duas raquetes em formas de barras laterais e uma bola que quica de um lado para o outro. Na obra de Melo, RePong, que é construído através do Processing, continua sendo um jogo em que a bola traça linhas aleatórias de cor e espessura. A ideia principal não é ganhar ou perder para a máquina, mas, sim, colaborar na criação de um trabalho ar- 
tístico. "O jogo não tem uma contagem de pontos, pois a qualquer momento pode ser interrompido pelo observador/usuário e seguindo os outros programas de desenho apresentados, cada game corresponde a uma imagem serializada, impressa apenas uma vez e apagada definitivamente da memória do computador". (MELO, 2014, p.51)

Ainda como processo digital, Melo (2014) apresenta a obra DesenhoAoVivo, 2013. Através da webcan, a imagem de um observador/participante, geralmente de um rosto, é captada e congelada pelo programa. Com a ajuda de uma mesa digitalizadora, o processo de desenhar se inicia e o desenho é projetado sobre um mural. Ainda sobre este anteparo, é possível delinear o traço perceptível com a projeção. Isso é realizado em alguns minutos e caracteriza um happing, pois as ações, como capturar e congelar a imagem, traçar com o auxílio da mesa digitalizadora e desenhar sobre o mural, podem ser desenvolvidas simultaneamente. Aqui, o artista convida o público, mais uma vez, a realizar a obra de arte. Há uma alternância de papéis, pois o observador/participante também pode convidar o artista para se retratar. Existe aqui a possibilidade de uma sobreposição de imagens, o que gera um hibridismo entre o espaço e o tempo, pois o resultado para a contemplação não distingue estes dois elementos. (MELO, 2014, p.51)

Distante da tela do computador, mas ainda evocando a dualidade homem e máquina, Melo (2014) propõe outra releitura da utilização da técnica spin art. Esta, criada na década de 1960, consiste em utilizar a rotação e o movimento centrífugo para produzir uma imagem sobre suportes como papel ou tela. Após esparramar a tinta sobre o suporte, a máquina é acionada. O resultado é uma pintura que combina uma ação mecânica e uma ação humana. O artista britânico, e também celebridade, Damien Hirst recorre a esta técnica para criar a série Spin Paintings. Melo (2014), no entanto, não se contenta em ter uma máquina estática, fixada em um ponto, como as originais propunham. A Máquina de Pintura se torna na exposição $A$ Arte Somos Nós um carrinho, podendo ser levada para fora dos espaços consagrados à arte pelo sistema. Mais uma vez ocorre uma mudança de paradigma quando o artista baiano propõe um ato mecânico que não deixa de ser único, tal qual uma obra de arte. Ao espalhar a tinta sobre o suporte, está realizando uma ação individual e subjetiva.

Por último, Melo (2014) descreve em sua exposição a performance Irreprodutibilidade, 2014. O próprio artista encena um ritual ao se apresentar descalço e sem camisa para o público. Diante de uma pilha de caixas de fósforos, inicia movimentos repetitivos para acender o fósforo. Este movimento consiste em colocar a caixa sobre o antebraço, próximo do cotovelo, e com a mesma mão, acender o fósforo. Ou seja, o artista propõe que o corpo humano, uma máquina, faça um movimento de $180^{\circ}$ e, em seguida, um giro de aproximadamente de 270 ㅇ para acender um fósforo. Mais uma vez, o público também é convidado a manusear da mesma forma o fósforo e a caixa.

Da complexidade da programação ao gesto mais simples, Melo (2014) e a curadoria colocam como o centro da questão a subjetividade e a corporalidade. Esta última é um veículo e sentido da experiência, "o corpo como uma matriz de símbolos e objetos de pensamento", como nos mostra Seeger, da Matta e Viveiros de Castro 
(1979, p.9). É neste sentido também que Lygia Clark propõe o que é subjetividade, uma expressividade. (MEDEIROS, 2009, p.7)

Merleau-Ponty também reflete sobre a experiência como um dos únicos caminhos a se reconhecer através do próprio corpo. É a relação do subjetivo e da corporalidade que permitirá ao sujeito encarar o que se está propondo.

Todo saber se instala nos horizontes abertos pela percepção. Não se pode tratar de descrever a própria percepção como um dos fatos que se produzem no mundo, já que a percepção é a "falha" deste "grande diamante". Certamente, o intelectualismo representa um progresso na tomada de consciência: aquele lugar fora do mundo que o filósofo empirista subentendia e onde tacitamente ele se situava para descrever o acontecimento da percepção recebe agora um nome, figura na descrição. [...] Ora, se o corpo próprio e o eu empírico são apenas elementos no sistema da experiência, objetos entre outros objetos sob o olhar do verdadeiro $\mathrm{Eu}$, como pudemos algum dia confundir-nos com nosso corpo, como pudemos acreditar que víamos com nossos olhos aquilo que na verdade apreendíamos por uma inspeção do espírito, como o mundo não é perfeitamente explícito diante de nós, por que ele só se desdobra pouco a pouco e nunca "inteiramente", enfim como ocorre que nós percebamos? Nós só o compreenderemos se o eu empírico e o corpo não forem imediatamente objetos, nunca se tornarem totalmente objetos, se houver um certo sentido em dizer que vejo o pedaço de cera com meus olhos e se, correlativamente, esta possibilidade de ausência, esta dimensão de fuga e de liberdade que a reflexão abre no fundo de nós e que chamam de Eu transcendental em primeiro lugar não forem dadas e nunca forem absolutamente adquiridas, se nunca puder dizer "Eu" absolutamente, e se todo ato de reflexão, toda tomada de posição voluntária se estabelecerem sobre o fundo e sobre a proposição de uma vida de consciência pré-pessoal. O sujeito da percepção permanecerá ignorado enquanto não soubermos evitar a alternativa entre o naturante e o naturado, entre a sensação enquanto estado de consciência e enquanto consciência de um estado, entre a existência em si e a existência para si. (MERLEAU-PONTY, 199. p.280-281)

A tomada de decisão voluntária proposta por Merleau-Ponty está presente nas obras indicadas pelo artista baiano. O que se observa na exposição A Arte Somos Nós é a dimensão de como a arte digital dá ao sujeito a possibilidade de autonomia. Ao movimentar o próprio corpo para ver na tela do computador um fazer artístico, o sujeito é levado ao status de coautor. Aqui não é somente a existência do sujeito que está em jogo, mas também a própria existência em si da obra de arte:

Trata-se de uma estratégia que fosse além da experiência estética, ou melhor, que despertasse a consciência do indivíduo a partir do embate direto com a obra, para que ele próprio desse sentido estético ao que lhe era apresentado e, ao fazê -lo, emancipar-se-ia das esferas da vida cultural, espiritual, econômica e política. Em "A Arte Somos Nós", Zimaldo Melo nos estimula ao prazer, ao gozo, e à satisfação da experiência ao colocar-nos como espectador ativo que faz a obra acontecer juntamente com o artista - por vezes com a máquina programada por ele. A troca de estímulos entre obra e espectador faz da fruição uma experiência singular, onde o ambiente expositivo se torna a plataforma viva da singularidade. (MIDLEJ, PORTELA, 2014, p.45) 


\section{Conclusão}

Sem dúvida o que a arte nos mostra, seja esta no meio digital ou não, é a existência. Merleau-Ponty reflete sobre o mundo que é ou não percebido, sobre a sensibilidade captada por nós e sobre nós mesmos, a ponto de compreender que homem e máquina são as partes de um todo. Em algumas vezes em um grau de dependência absurda, em outras, como um mera necessidade passageira. O que vale, para o filósofo francês, é a experiência.

Nesse sentido, a exposição $A$ Arte Somos Nós reflete sobre o homem e a máquina, a máquina e o homem como máquina. Não é somente um convite para uma coautoria. $\mathrm{A}$ poética está no binômio homem/máquina, no entendimento do mundo que estamos inseridos, na cultura-mundo criada, como diz Serroy e Lipovestky, que faz do artista o produto, a celebridade, e não mais a obra como produto, passível de acesso por um público.

Oferecer ao sujeito/observador o papel de artista é questionar a própria aura do autor da obra, que vem se sacralizando ao longo dos tempos. É a prática da alteridade, pois o outro será, pelo menos na proposta do artista baiano, o agente integrante da obra. Aí, quando o programa computacional faz com que exista a captação de face e som para produzir a "tinta" num espaço virtual, entendemos que estamos fazendo arte, inseridos ambos, homem e máquina, como código, num processo criativo. Aqui há a presença da subjetividade e corporalidade pretendida por Lygia Clark e Hélio Oiticica.

Quanto à máquina, esta se torna o suporte. Como Tassanari pontua em seu ensaio, os questionamentos começaram com Cézzane, mas o desdobramento da arte ainda está ocorrendo. Este entendimento é importante, pois se não existisse a máquina para armazenar estas informações, os códigos, não poderíamos dar um passo adiante no que se relaciona à arte. No fazer da arte, há sempre o conceito de transversalidade, pois o diálogo é constante com os núcleos estruturantes da sociedade. E a cultura digital é um deles.

E o homem? O que se questionou também nessa exposição foi o homem na condição de máquina. Os gestos repetidos do acender o fósforo, a utilização do antebraço para movimentos contínuos e a indução, por parte do artista, ao poder efêmero de "acender um fósforo de maneira diferente" são atos que nos revelam o quanto o corpo é um suporte de ações que sacralizam o indivíduo. A performance ganha o título de Irreprodutível porque remete ao ideal do subjetivo, cunhado tão bem no romantismo. Argan está certo: o romantismo está presente na obra de arte contemporânea. Isso faz com que o valor aurático da obra permaneça intacto, não se tratando apenas do sujeito como celebridade, mas tornando a própria obra elemento permanente no imaginário de quem a observa. Dessa maneira, o que a cultura digital preserva é, exatamente, a expansão da própria arte. 


\section{Referências}

ARANTES, Priscila. arte e Mídia - Perspectivas da estética digital. São Paulo, Editora Senac, 2005.

ARGAN, Giulio Carlo. Clássico e Romântico. In: Arte Moderna. São Paulo, Companhia das Letras, 2004.

CLARK, Lygia, GULLAR, Ferreira, Pedrosa, Mário. Lygia Clark - Arte Brasileira Contemporânea. Rio de Janeiro, FUNARTE, 1980.

DIAS, RMS. Notas introdutórias de uma analítica no campo das modelizações vocacionais. In JACÓ-VILELA, AM., CEREZZO, AC., and RODRIGUES, HBC., orgs. Clio-psyché: fazeres e dizeres psi na história do Brasil [online]. Rio de Janeiro: Centro Edelstein de Pesquisas Sociais, 2012. p. 262-274. ISBN: 978-85-7982-061-8. Available from SciELO Books < books.scielo.org>.

FRICKE, Christiane. Novos Medioa. WALTHER, Ingo F. (org.). In Arte do Século XX. Köln, Taschen, 2010.

HARRISON, Charles.Modernismo. São Paulo, Cosac \&Naify, 2001.

HAUSER, Arnold. Rococó, Classicismo e Romantismo. In: A História Social da Arte e da Literatura. São Paulo, Martins Fontes, 2003.

LÉVY, PIERRE. Entrevista Pierre Lévy. Revista ComCiência, versão online no 131. Campinas, 2011. Disponível em http://comciencia.scielo.br/scielo.php script=sci_arttext\&pid=S1519-76542011000700013\&lng=pt\&nrm=iso. Acesso em 14 jun 2014.

LIPOVETSKY, Gilles; SERROY, Jean. O mundo como imagem e como comunicação. In: A cultura-mundo. São Paulo, Companhia das Letras, 2008.

MANSANO, Sonia Regina Vagas. Sujeito, subjetividade e modos de subjetivação na contemporaneidade. São Paulo, UNESP, 2009. Disponível em http://www2.assis. unesp.br/revpsico/index.php/revista/article/viewFile/139/172. Acesso em 05 set 2014.

MIDLEJ, Dilson, PORTELA, Antonio Carlos. Texto Curatorial da exposição A Arte Somos Nós. In _____ A Arte Somos Nós: questionamentos sobre o papel do fruidor na hipermodernidade. Cachoieira, 2014. Disponível em http://pt.scribd.com/doc/223079270/A-ARTE-SOMOS-NOS-questoes-sobre-o-papel-do-fruidor-na-hipermodernidade. Acesso em 02 set 2014. 
MEDEIROS, Izabella Maria. A Relação entre o corpo e subjetividade na obra de Lygia Clark. Maceió, 2009. Disponível em http://abrapso.org.br/siteprincipal/images/ Anais_XVENABRAPSO/185.\%20a\%20rela\%C7\%C3o\%20entre\%20corpo\%20e\%20 subjetividade\%20na\%20obra\%20de\%20lygia\%20clark.pdf. Acesso em 13 jun 2014.

MELO, Zimaldo. A Arte Somos Nós: questionamentos sobre o papel do fruidor na hipermodernidade. Cachoieira, 2014. Disponível em http://pt.scribd.com/doc/223079270/A-ARTE-SOMOS-NOS-questoes-sobre-o-papel-do-fruidor-na-hipermodernidade. Acesso em 12 abril 2014.

MERLEAU-PONTY, Maurice. O mundo percebido. In: Fenomologia da Percepção. São Paulo, Martins Fontes, 1999.

MIRANDA, Luciana Lobo. Subjetividade: a (des)construção de um conceito. In: Subjetividade em questão: a infância como crítica da cultura. (Org.: SOUZA, Solange Jobim). Rio de Janeiro, 7Letras, 2005.

SEEGER, Anthony; da MATTA, Roberto; VIVEIROS de CASTRO, E.B. A Construção da Pessoa nas Sociedades Indígenas. Rio de Janeiro, Boletim do Museu Nacional, 1979. Disponível em

TASSINARI, Alberto. O Espaço Moderno. São Paulo, Cosac Naif, 2001.

\section{Autora}

Vaneza Rita Silva Melo

Universidade Federal do Recôncavo da Bahia

Jornalista e graduanda em Arte Visuais

Cachoeira, Bahia, Brasil

vanezamelo@gmail.com 